\title{
Measurement of Clinical Pharmacy Key Performance Indicators to Focus and Improve Your Hospital Pharmacy Practice
}

\author{
Elaine Lo, Daniel Rainkie, William M Semchuk, Sean K Gorman, Kent Toombs, Richard S Slavik, \\ David Forbes, Andrea Meade, Olavo Fernandes, and Sean P Spina
}

\section{INTRODUCTION}

C linical pharmacy is defined as "a health science discipline ${ }_{i}$ in which pharmacists provide patient care that optimizes medication therapy and promotes health, wellness, and disease prevention" and "embraces the philosophy of pharmaceutical care." The role of the clinical pharmacist is to promote safe, effective, and cost-conscious drug therapy and improve patient outcomes. ${ }^{2}$

Published evidence from observational studies, randomized controlled trials, and systematic reviews has shown that clinical pharmacist activities improve patient, medication, and surrogate outcomes; reduce health resource utilization and costs; reduce morbidity and mortality; and improve patients' quality of life..$^{3-6}$ Despite published evidence supporting the benefits of clinical pharmacy services for health and economic outcomes, quantitative expressions that describe whether or how often a process of care or outcome of care occurs, also known as performance indicators, must be monitored to ensure that these services are delivered consistently. However, until recently, there was no established consensus as to which activities are key indicators of clinical pharmacy performance. A grass-roots collaborative of Canadian hospital pharmacists recently addressed this unanswered question by systematically establishing clinical pharmacy key performance indicators (cpKPIs) using a Delphi technique. ${ }^{7}$ Some questions remain, including "What activities do pharmacists perform, and how consistently do they perform them?" To answer these questions, we first must understand what cpKPIs are; why cpKPIs should be measured and reported; who will be affected by these measurements; where and how cpKPIs can be measured, reported, and utilized: and when we should begin to capture cpKPIs. This article aims to address these questions about cpKPI adoption and measurement from multiple perspectives (including those of front-line pharmacists, leadership, external stakeholders, and the public), supplemented by examples from the authors' experience.

\section{WHAT ARE cPKPIs?}

Key performance indicators are quantifiable measures of quality that can be used to track an organization's progress toward achieving intended goals related to process inputs, process outputs, or outcomes. ${ }^{8}$ These indicators are discrete events that, when they occur for an individual patient, have been proven to result in a positive outcome for that person. The US Agency for Healthcare Research and Quality (AHRQ) defines a process measure as "a health care-related activity performed for, on behalf of, or by a patient" and assesses the activities carried out by health care professionals to deliver services. ${ }^{9}$ These types of measures are most useful when there is strong evidence associating processes with clinically important outcomes. The AHRQ defines an outcome measure as "a health state of a patient resulting from health care", noting that such measures can encompass a vast range of health states, including physiologic measurements, laboratory test results, or a patient's symptoms, morbidity, functional state, and quality of life. ${ }^{10}$ Many "outcome measures" actually employ processes of care or use of services (e.g., hospital readmission rates) as "proxies" for patients' health states. Key performance indicators differ from workload measurement or workload management because they are selected on the basis of a proven association with a positive patient outcome, whereas workload measurement or management counts the frequency of an activity that is not necessarily specifically known to affect outcomes for individual patients. Moreover, a cpKPI would be selected only if the specific activity or event had been proven to have a positive effect on patient outcome.

Fernandes and others ${ }^{7}$ indicated that a cpKPI should fulfill the following criteria: reflect a desired quality of practice, link to direct patient care, be supported by evidence of an impact on meaningful patient outcomes, be pharmacy- or pharmacistsensitive, and be feasible to measure. The Delphi rounds resulted 
in identification of $8 \mathrm{cpKPIs}$ (Table 1), which fell into 6 clinical pharmacy critical activity areas: admission medication reconciliation, interprofessional patient care rounds, pharmaceutical care, discharge medication reconciliation, patient education or discharge counselling, and bundled critical activity areas. ${ }^{7}$

\section{WHY CAPTURE cPKPIs?}

The Canadian consensus cpKPIs were developed to support improvement in the quality of patient care and to advance evidence-informed clinical pharmacy practice. They can help to delineate the patient care expectations of a clinical pharmacist, describe standards of practice, permit benchmarking within and between organizations, and elevate professional accountability and transparency. ${ }^{7}$ The collaborative of Canadian hospital pharmacists (now becoming known as the Canadian National cpKPI Collaborative), with its strong stake in clinical pharmacy practice, overwhelmingly agreed that measuring the 8 consensus cpKPIs would be useful in advancing clinical pharmacy practice and improving the quality of patient care. Validation of the importance of cpKPIs came from nonpharmacist stakeholders who agreed or strongly agreed that measuring the 8 national cpKPIs would be useful in advancing clinical pharmacy practice and improving the quality of patient care. ${ }^{11}$

Focusing on activities that have been shown to decrease morbidity and hospital readmission increases the likelihood that a pharmacist's work will contribute to positive patient outcomes. The cpKPIs can provide practical guidance to assist in prioritizing a pharmacist's work and articulating patient care expectations. Front-line pharmacists and pharmacy leaders can collaboratively use cpKPIs as tools for self-reflection and for identifying improvement opportunities to advance practice. For example, at the Nova Scotia Health Authority_Central Zone, cpKPI data are shared among clinical pharmacy team members to generate discussion and inspire creative solutions to prioritize tasks, streamline workflow, and avoid redundancy. Examples of the successful use of cpKPIs include liaising with charge nurses to capture opportunities for discharge medication reconciliation and creating a handover mechanism for pharmacists taking over care of a service, to avoid duplication.

Pharmacy leaders and hospital administrators are charged with ensuring that pharmacists provide the best care for patients within a given budget, thus supporting the effective use of health care resources. In some organizations, cpKPI data have been presented to quality committees, senior management, and boards. For example, at the Regina Qu'Appelle Health Region and the Vancouver Island Health Authority, data are shared with senior management to demonstrate the value of pharmacists in diverse areas. Capturing the resolution of drug therapy problems (DTPs) that involve high-alert drugs (as defined by the US Institute for Safe Medication Practices) has helped to demonstrate the impact of pharmacists on medication and patient safety. At the University Health Network in Toronto, Ontario, cpKPIs form part of the organization's balanced scorecard.

Demonstrating the value of clinical pharmacy services within business plans has become increasingly important as health authorities are required to make difficult choices about resource allocation to optimize patient care. By capturing the value of clinical pharmacy services through measurement of cpKPIs, administrators and managers have access to data that may support maintaining or expanding clinical pharmacy services to provide appropriate evidence-based care. For example, at the Interior Health Authority in British Columbia, pharmacist positions have been created on the basis of cpKPI data to justify pharmacy services. In defending pharmacy resources during periods of financial stress, cpKPI data can serve as a powerful tool for maintaining pharmacy services. Recently, with support from cpKPI data, leaders of the Regina Qu'Appelle Health Region were successful in protecting pharmacist positions against budget restraint measures.

Pharmacy managers may use cpKPI data to evaluate and enhance patient care activities. Process measurement, such as counting the number of patients who have received specific

\section{Table 1. The 8 National Clinical Pharmacy Key Performance Indicators (cpKPIs) ${ }^{7}$}

\begin{tabular}{ll} 
cpKPI & \multicolumn{1}{c}{ Description } \\
\hline Medication reconciliation on admission & $\begin{array}{l}\text { Proportion of patients who receive documented admission medication reconciliation } \\
\text { (as well as resolution of identified discrepancies) performed by a pharmacist }\end{array}$ \\
\hline Pharmaceutical care plan & $\begin{array}{l}\text { Proportion of patients for whom pharmacists have developed/initiated a pharmaceutical } \\
\text { care plan }\end{array}$ \\
\hline Drug therapy problems & Number of drug therapy problems addressed by a pharmacist per admission \\
\hline Interprofessional patient care rounds & $\begin{array}{l}\text { Proportion of patients for whom pharmacists participate in interprofessional patient care } \\
\text { rounds to improve medication management }\end{array}$ \\
\hline Patient education during hospital stay & $\begin{array}{l}\text { Proportion of patients who receive education from a pharmacist about their disease(s) } \\
\text { and medications(s) during their hospital stay }\end{array}$ \\
\hline Patient education at discharge & Proportion of patients who receive medication education by a pharmacist at discharge \\
\hline Medication reconciliation at discharge & $\begin{array}{l}\text { Proportion of patients who receive documented discharge medication reconciliation and } \\
\text { resolution of identified discrepancies by a pharmacist }\end{array}$ \\
\hline Bundled patient care interventions & $\begin{array}{l}\text { Proportion of patients who receive comprehensive direct patient care from a pharmacist } \\
\text { working in collaboration with the health care team }\end{array}$ \\
\hline
\end{tabular}


cpKPI activities in relation to the total number of patients, can elevate the professional accountability of pharmacists and provide recognition for their work. Adopters of measurement programs in health care have witnessed improvement in performance over time. ${ }^{12}$ At the Interior Health Authority, pharmacists capture 3 aspects of a resolved DTP: disease state, drug, and intervention. Feedback based on the captured aggregate data across the organization is given to all clinical pharmacists, as a group, to encourage practice toward resolving DTPs that are predefined as reflecting the highest-quality evidence-based pharmacotherapy interventions, such as adding an angiotensin-converting enzyme inhibitor for a patient with heart failure in the absence of contraindications. Nonetheless, cpKPIs represent only one type of indicator on the performance dashboard, and there are many components of a pharmacist's work that these indicators do not capture.

The publicly funded health care system is increasingly required to be accountable for the value it provides. Across Canada, the provinces allocate, on average, about 38 cents of every budgeted dollar toward health care. ${ }^{13} \mathrm{~A}$ recent newspaper article stated that $\$ 3.6$ billion was spent to fund 10000 physicians in 2011/2012, with no mechanism on the government's part to ensure that physician services are achieving value for money. ${ }^{14}$ The same scrutiny should be imposed on pharmacists in the future as budget pressures continue to escalate. Data for cpKPIs may be useful metrics to better inform taxpayers and external stakeholders on the value of pharmacists to patient care.

\section{WHO IS AFFECTED BY cPKPIs?}

The ultimate goal of cpKPI measurement and reporting is to advance clinical pharmacy practice and thus to improve the quality of patient care. Patients are affected by the care they receive from pharmacists who deliver high-value activities proven to optimize outcomes. Targeting a consistent suite of cpKPIs may result in the establishment of expectations of pharmacist services for patients and the health care team. Front-line pharmacists are tasked with providing and documenting their care in collaboration with other care team members. Measuring and reporting cpKPIs will also affect other stakeholders, including pharmacy leadership, interprofessional team members, and nonpharmacy administrators. Pharmacy leadership analyzes and evaluates the cpKPI data generated to better understand the gaps in knowledge and skills of their pharmacists in order to support their professional development.

\section{WHERE ARE cPKPIS BEING CAPTURED?}

Some sites, such as the Regina Qu'Appelle Health Region in Saskatchewan and the University Health Network in Toronto, started capturing select cpKPIs over a decade ago, and other sites are now beginning to collect designated indicators. These more recent adopters include the Vancouver Island Health Authority and the Interior Health Authority in British Columbia, as well as the Nova Scotia Health Authority-Central Zone. Along with site-specific data capture, the Canadian National cpKPI Collaborative has begun initial groundwork for the development of a national registry of Canadian cpKPIs, to facilitate data collection at individual sites and analysis at the local level and then more broadly using a comparative national analysis.

At the University Health Network, for example, a clinical metrics "cross-walk" document was developed through live focus groups, during which front-line pharmacists summarized their opinions about desired attributes for a cpKPI-capture system. "Easy to use and intuitive" was voted by most sites as an important attribute for success in capturing these data. For example, building tracking into existing electronic patient care systems, designing a data-entry interface with tick box predominance, and auto-populating fields are features that achieve ease of use. The authors of the current article conducted semistructured interviews with Canadian pharmacy leaders known to be involved in cpKPI, which showed that various cpKPI collection strategies are currently in place, including paper-based collection, hospital-wide electronic health records, Microsoft Access databases (Microsoft; https://products.office.com/en-ca/access), HanDBase software (DDH Software Inc; www.ddhsoftware.com/ handbase.html), Emerald Health Information Systems (www.emeraldhis.com/), and Google Forms (https:// www.google. $\mathrm{ca} /$ forms/about). Examples of cpKPIs that are tracked nationally by these organizations are described in Table 2 .

At sites with established clinical intervention tracking programs, a shift to collecting cpKPI may be less of a challenge than at sites that do not currently track pharmacist clinical interventions on a routine basis. Barriers and proposed solutions, based on the current authors' experiences, are summarized in Table 3.

Front-line pharmacists may not routinely track clinical metrics; therefore, an implementation challenge arises when these pharmacists do not see the authentic, multidimensional value of capturing cpKPIs and instead perceive their integration as a top-down mandate. Most pharmacists are inspired by influential patient care enhancements. As such, reiterating how performing cpKPI activities has been shown to positively influence morbidity and readmission is important. Harmonizing cpKPIs with local and health region priorities, Accreditation Canada, and CSHP 2015 paints the "big picture" and helps to align priorities.

Rather than convincing front-line staff to "buy in" to pre-set ideas, leaders can actively seek the support of pharmacists by instilling an authentic sense of "ownership" and involving staff members in meaningful cpKPI decision-making. Pharmacists value the efficiency of a system that captures data in a fashion that minimizes time taken away from patient care. The University Health Network and the Nova Scotia Health Authority_Central 
This single copy is for your personal, non-commercial use only.

For permission to reprint multiple copies or to order presentation-ready copies for distribution, contact CJHP at cjhpedit@cshp.ca

Table 2. Sample of cpKPIs Currently Being Captured across Canada

\begin{tabular}{|c|c|c|c|c|c|}
\hline cpKPI Captured & $\begin{array}{l}\text { Vancouver Island } \\
\text { Health Authority } \\
\text { (BC) }\end{array}$ & $\begin{array}{l}\text { Interior Health } \\
\text { Authority } \\
\text { (BC) }\end{array}$ & $\begin{array}{l}\text { Qu'Appelle } \\
\text { Health Region } \\
\text { (SK) }\end{array}$ & $\begin{array}{l}\text { University Health } \\
\text { Network } \\
\text { (ON) }\end{array}$ & $\begin{array}{c}\text { Nova Scotia } \\
\text { Health } \\
\text { Authority (NS) }\end{array}$ \\
\hline $\begin{array}{l}\text { Medication reconciliation } \\
\text { on admission }\end{array}$ & $\sqrt{ }$ & $\sqrt{*}$ & $\sqrt{ }$ & $\sqrt{ }$ & $\sqrt{ }$ \\
\hline Pharmaceutical care plan & & $\sqrt{*}$ & & $\sqrt{+}$ & $\sqrt{ }$ \\
\hline Drug therapy problem & $\sqrt{ }$ & $\sqrt{ }$ & $\sqrt{ }$ & & $\sqrt{ }$ \\
\hline Disease & & $\sqrt{ }$ & $\sqrt{ }$ & & \\
\hline Drug & $\sqrt{ }$ & $\sqrt{ }$ & $\sqrt{ }$ & & \\
\hline Type & $\sqrt{ }$ & $\sqrt{ }$ & $\sqrt{ }$ & & \\
\hline $\begin{array}{l}\text { Significance and likelihood } \\
\text { of future event }\end{array}$ & $\sqrt{ }$ & & & & \\
\hline Interprofessional patient care rounds & $\sqrt{ }$ & $\sqrt{*}$ & $\sqrt{ }$ & $\sqrt{t}$ & $\sqrt{ }$ \\
\hline Patient education during hospital stay & $\sqrt{ }$ & $\sqrt{*}$ & $\sqrt{ }$ & $\sqrt{+}$ & $\sqrt{ }$ \\
\hline Patient education at discharge & $\sqrt{ }$ & $\sqrt{*}$ & & $\sqrt{+}$ & $\sqrt{ }$ \\
\hline Medication reconciliation at discharge & $\sqrt{ }$ & $\sqrt{*}$ & & $\sqrt{ }$ & $\sqrt{ }$ \\
\hline Bundled patient care interventions & & $\sqrt{*}$ & & $\sqrt{+}$ & $\sqrt{ }$ \\
\hline Data-capture software & $\begin{array}{c}\text { Microsoft } \\
\text { Access database }\end{array}$ & HanDBase & Google Forms & $\begin{array}{l}\text { Hospital-wide } \\
\text { electronic } \\
\text { health record }\end{array}$ & $\begin{array}{l}\text { Emerald Health } \\
\text { Information } \\
\text { Systems }\end{array}$ \\
\hline Users of data & $\mathrm{F}, \mathrm{S}$ & $F, S, E$ & $\mathrm{~F}, \mathrm{~S}$ & $F, S, E$ & F, S \\
\hline
\end{tabular}

Zone are examples of organizations where cpKPIs were rolled out through a grass-roots movement championed by inspired (and inspiring) front-line pharmacists. Such active leadership by frontline staff can enhance momentum and acceptance for cpKPI capture among peer pharmacists.

\section{WHAT ARE THE BENEFITS OF CAPTURING cPKPIs?}

The Interior Health Authority has used trend analysis to provide insight into processes over time. Unpublished data collected between 2009 and 2014 were used to define strategies pertaining to pharmacists' deployment to care areas. These data showed that pharmacists who were integrated into care teams were more effective than pharmacists who performed troubleshooting on multiple wards. Within the data, it was apparent that the majority of resolved DTPs had occurred at tertiary care centres, rather than rural centres. These data are useful for ensuring that pharmacist resources are aligned to generate the greatest clinical impact. Finally, the data are useful in performance evaluation, as they allow discussion of personalized trends in resolved DTPs over time, rather than an absolute number or quota.

One of the goals of capturing cpKPIs, especially in a national database, is to standardize, advance, and benchmark (internally and externally) clinical pharmacy practice. By developing comparison strategies, we can share and learn best practices and advance the profession. A challenge in setting benchmarks is deciding on the appropriate denominator.
Translating the cpKPI data into information that is useful to the public and external stakeholders is critical. For example, Mourao and others ${ }^{11}$ found in their stakeholder feedback study that discharge medication reconciliation was the cpKPI most likely to influence decisions to fund or use clinical pharmacist services among nonpatient stakeholders. Several approaches have been taken by health authorities to assist external stakeholders in understanding cpKPI data:

- Evidence-based extrapolation: An extrapolation was performed by the Interior Health Authority on the basis of RCT data ${ }^{5,6}$ (see Table 4). The organization's press release for Pharmacy Day 2014 ${ }^{16-18}$ presented cumulative data for resolved DTPs and explained how the data translated into reductions in emergency room visits, drug-related readmissions, and overall system costs.

- Real-life correlation: In an observational cohort study, the University Health Network tracked outcomes for 8678 patients who received a select cPKPI-based intervention on one internal medicine ward over 5 years. With adjustment through propensity analysis in this small pilot study, the organization detected a nonsignificant trend (reduction in 30-day hospital visits and readmissions by $2 \%$ ) that can be explored more comprehensively in larger studies. ${ }^{19}$ Converting abstract cpKPI data into tangible outcomes (such as hospital readmissions averted and monetary worth) helps the public, as well as nonpharmacist senior management, to appreciate the value contributed by clinical pharmacists.

- Heat matrix: For each resolved DTP, pharmacists at the Vancouver Island Health Authority estimate the clinical 
This single copy is for your personal, non-commercial use only.

For permission to reprint multiple copies or to order presentation-ready copies for distribution, contact CJHP at cjhpedit@cshp.ca

Table 3. Purposes, Challenges, and Solutions of Implementing Clinical Pharmacy Key Performance Indicators (cpKPIs)

Rationale and Utility of cpKPIs Barriers and Challenges

Authors' Proposed Solutions

Front-line pharmacists

Provide reference summary of:

Time required to

document cpKPIs

- Activities proven to improve outcomes

- Priority of patient care activities to optimize impact on outcomes

- Pharmacists' role that can be promoted to other members of interdisciplinary team

- Performance expectations with the employer

\section{Complexity of indicator} documentation

Cost

Daily tracking and

reporting consistency

\section{Practice leaders and pharmacy managers}

Provide reference summary for: pharmacy services

- Justifying expansion of clinical pharmacy services

- Explaining value and estimating return on investment in clinical pharmacy services

- Determining effectiveness and efficiency of clinical pharmacy services

- Setting benchmarks

- Performance management
- Justifying prioritization of scarce clinical
Front-line staff ownership and uptake

Lack of accuracy and precision
- Automate data collection where possible (e.g., self-populated patient name and medical record number)

- Enable pull-down data entry at point of care

- Incorporate into electronic health care system

- Simplify platform for documentation; e.g., check boxes

- Collect minimal amount of required information

- Use existing or least expensive hardware and software data platforms

- Make it a daily routine for all pharmacists

- Pharmacist-to-pharmacist accountability

- Live capture or end-of-day input

- Access and use cpKPI knowledge mobilization kit*

- Regularly present collected data to staff

- Engage front-line staff in change management and leadership processes

- Provide training during orientation and interim audits

- Facilitate understanding to resolve local apprehension

Effective change management $\bullet$ Change management strategies

to implement and sustain

cpKPls with everyday practice

Trend analysis • Set benchmarks through comparison between clinical wards, hospitals, or health regions

- Be cautious in analyzing trends

Patient, taxpayers, external stakeholders

Provide reference summary of:

- Clinical pharmacists' role

- Activities proven to improve patient outcomes

- Patient expectations

- Activities to ensure pharmacist accountability

- Appropriate use of resources to promote a more sustainable health care system
Comprehension and interpretation of cpKPI data
- Correlate with and extrapolate to meaningful patient outcomes (e.g., hospital readmissions), with recognized limitations

- Explain the clinical significance of cpKPls

- Tailor presentation according to the interest of audience

- Acknowledge limitations of reporting isolated indicators versus a dashboard of indicators

- Acknowledge differences in systems and human resources across heterogeneous sites

*This kit is now available at www.cshp.ca/productsServices/cpKPI/index_e.asp

Table 4. Evidence-Based Extrapolation Performed by the Interior Health Authority, British Columbia ${ }^{15}$

Outcome

Reduction in visits to emergency department

Reduction in hospital visits

Reduction in drug-related readmissions

Reduction in readmissions

Estimated cost saving

*Based on data from randomized controlled trials.,

†Based on 155701 drug therapy problems resolved from January 1, 2009, to December 31, 2014.

The ratio extrapolation assumes a similar number of drug therapy problems resolved per patient, and similar direct and indirect costs from original trials.
Relative Reduction*

ual Event

Reduction Ratet

19 177/year

$16 \% \quad 21804 /$ year

$80 \% \quad 15689 /$ year

$20 \%$

2 506/year

$\$ 230 /$ patient

$\$ 19$ million


significance of the potential adverse outcome associated with the problem and the likelihood of that outcome occurring had there not been an intervention. This "heat map" provides a visual representation of the risk to patients that has been averted as a consequence of clinical pharmacy services (Figure 1). This approach was adapted from the Hazard Scoring Matrix promoted by the Institute for Safe Medication Practices. ${ }^{22}$

- Tailor to your audience: Pharmacists may more effectively deliver their message by tailoring key information in their presentations to the interest most valued by their specific audience.

\section{WHEN SHOULD WE START CAPTURING cpKPIs?}

With the publication of a nationally agreed upon group of cpKPIs, it is appropriate to start capturing these indicators across Canada now.

\section{CONCLUSION}

With the recent publication of systematically developed consensus cpKPIs, a nationwide database capturing cpKPIs from multiple institutions may be feasible in the foreseeable future. Implementing, measuring, and reporting cpKPIs will have many advantages. For pharmacists, a defined list of cpKPIs can serve as a basis for prioritizing patient care activities. For leadership, cpKPI data can be used to demonstrate practitioner value, can provide metrics for evaluating improvement initiatives, and can inform performance evaluation. For patients, information on cpKPI measurements can demonstrate accountability and illustrate the impact of pharmacists on patient care. As a whole, cpKPIs contribute to improved patient care and advance the profession of hospital pharmacy. In time, consensus cpKPIs can be developed for primary care and community-based practices. The time to capture cpKPIs is now!

\begin{tabular}{|c|c|c|c|c|c|c|}
\hline \multirow{2}{*}{\multicolumn{7}{|c|}{$\begin{array}{c}\text { Key to Risk Levels } \\
\text { Low }\end{array}$}} \\
\hline & & & & & & \\
\hline Moderate & \multirow[b]{2}{*}{$\begin{array}{c}\text { No } \\
\text { Significance }\end{array}$} & \multirow[b]{2}{*}{$\begin{array}{c}\text { Minor } \\
\text { Significance }\end{array}$} & \multirow[b]{2}{*}{$\begin{array}{c}\text { Moderate } \\
\text { Significance }\end{array}$} & \multirow[b]{2}{*}{$\begin{array}{r}\text { Major } \\
\text { Significance }\end{array}$} & \multirow[b]{2}{*}{$\begin{array}{l}\text { Extremely } \\
\text { Significant }\end{array}$} & \multirow[b]{2}{*}{$\begin{array}{c}\text { Total } \\
\text { Significance }\end{array}$} \\
\hline $\begin{array}{c}\text { High } \\
\text { Extreme }\end{array}$ & & & & & & \\
\hline \multicolumn{7}{|l|}{2015} \\
\hline Not Likely & 532 & 639 & 133 & 66 & 2 & 1372 \\
\hline Possible & 22 & 2689 & 4567 & 958 & 114 & 8350 \\
\hline Likely & 6 & 279 & 1998 & 1051 & 133 & 3467 \\
\hline Almost certain & 22 & 146 & 419 & 349 & 227 & 1163 \\
\hline 2015 - Total & 582 & 3753 & 7117 & 2424 & 476 & 14352 \\
\hline Grand Total & 582 & 3753 & 7117 & 2424 & 476 & 14352 \\
\hline
\end{tabular}

Figure 1. "Heat matrix" from the Vancouver Island Health Authority for the period April 1 to October 1, 2015. Data values represent numbers of resolved drug therapy problems (DTPs) in each risk category, where the risk categories are defined by estimates of the clinical significance of the potential adverse outcomes and the likelihood of those outcomes occurring had there not been an intervention. "No significance" means that the DTP had no clinical importance for the patient. "Minor significance" means that the DTP was of little clinical importance for the patient; small adjustments to therapy were required but were not expected to significantly alter hospital stay, resource utilization, or clinical outcome. "Moderate significance" means that the DTP required intervention leading to moderate benefit for the patient; adjustments to therapy were expected to enhance the effectiveness of drug therapy, producing minor reductions in patient morbidity or treatment costs. "Major significance" means that the DTP required an intervention to prevent a moderate to major or reversible detrimental effect or the DTP required an adjustment of therapy on the basis of accepted evidence-based guidelines. "Extremely significant" means that the DTP required an intervention to save the patient's life or to prevent severe or irreversible detrimental effects. The aforementioned significance criteria were adapted from Kumar and others ${ }^{20}$ and Blix. ${ }^{21}$ 
This single copy is for your personal, non-commercial use only.

For permission to reprint multiple copies or to order presentation-ready copies for distribution, contact CJHP at cjhpedit@cshp.ca

References

1. American College of Clinical Pharmacy. Definition of clinical pharmacy. Pharmacotherapy. 2008;28(6):816-7.

2. Canadian hospital pharmacy 2015 ( CSHP 2015). Ottawa (ON): Canadian Society of Hospital Pharmacists; 2008 [cited 2015 Mar 1]. Available from: www.cshp.ca/dms/dmsView/2_CSHP-2015-Goals-and-Objectives-Feb25\%2707-w-Appdx-rev-May\%2708.pdf

3. Bond C, Raehl CL. Clinical pharmacy services, pharmacy staffing, and adverse drug reactions in United States hospitals. Pharmacotherapy. 2006; 26(6):735-47

4. Kaboli PJ, Hoth AB, McClimon BJ, Schnipper JL. Clinical pharmacists and inpatient medical care: a systematic review. Arch Intern Med. 2006;166(9):955-64.

5. Gillespie U, Alassaad A, Henrohn D, Garmo H, Hammarlund-Udenaes $\mathrm{M}$, Toss $\mathrm{H}$, et al. A comprehensive pharmacist intervention to reduce morbidity in patients 80 years or older: a randomized controlled trial. Arch Intern Med. 2009;169(9):894-900.

6. Makowsky MJ, Koshman SL, Midodzi WK, Tsuyuki RT. Capturing outcomes of clinical activities performed by a rounding pharmacist practicing in a team environment: the COLLABORATE study. Med Care. 2009; 47(6):642-50.

7. Fernandes O, Gorman SK, Slavik RS, Semchuk WM, Shalansky S, Bussières JF, et al. Development of clinical pharmacy key performance indicators for hospital pharmacists using a modified Delphi approach. Ann Pharmacother. 2015;49(6):656-69.

8. Doucette D. Should key performance indicators for clinical services be mandatory? The "pro" side. Can J Hosp Pharm. 2011;64(1):55-6.

9. National Quality Measures Clearinghouse: selecting process measures for clinical quality measurement. Rockville (MD): Agency for Healthcare Research and Quality; 2014 [cited 2015 May 23]. Available from: www.qualitymeasures.ahrq.gov/tutorial/ProcessMeasure.aspx

10. National Quality Measures Clearinghouse: selecting health outcome measures for clinical quality measurement. Rockville (MD): Agency for Healthcare Research and Quality; 2014 [cited 2015 May 23]. Available from: www.qualitymeasures.ahrq.gov/tutorial/HealthOutcomeMeasure.aspx

11. Mourao D, Rayond C, Slobodan J, Gorman S, Toombs K, Doucette D, et al. How do patient, non-patient and hospital pharmacist stakeholder perspectives on clinical pharmacy key performance indicators for hospital pharmacists compare? [abstract]. Can J Hosp Pharm. 2015;68(1):70.

12. Chassin MR, Loeb JM, Schmaltz SP, Wachter RM. Accountability measures — using measurement to promote quality improvement. $N$ Engl J Med. 2010;363(7):683-8.

13. National health expenditure trends, 1975 to 2013 (executive summary). Ottawa (ON): Canadian Institute for Health Information; 2014 [cited 2015 Mar 1]. Available from: www.cihi.ca/CIHI-ext-portal/pdf/internet/NHEX_ EXEC_SUM_2013_EN

14. Bailey I. B.C. auditor-general questions value of doctors' pay. Globe and Mail [Toronto]. 2014 Feb 20 [cited 2015 Mar 1]:1-2. Available from: www. theglobeandmail.com/news/british-columbia/bc-auditor-general-questionsvalue-of-doctors-pay/article17017350/

15. Slavik RS. Pharmacy: trusted care when and where you need it [oral presentation]. Interior Health Pharmacy Awareness Month Campaign; 2015 Mar 25; Kelowna (BC).

16. Pharmacy Day highlights vital role of teams throughout Interior Health [news release]. Kelowna (BC): Interior Health Authority; 2014 Mar 14.

17. Pharmacy Day in B.C. Interior Daily News [Penticton (BC)]. 2014 Mar 24.

18. Pharmacy Day in B.C. The Nelson Daily [Nelson (BC)]. 2014 Mar 24.

19. Baker M, Bell C, Xiong W, Etchells E, Rossos P, Shojania K, et al. Does interprofessional medication reconciliation from admission to discharge reduce post-discharge patient emergency department visits and hospital readmissions [abstract]. Pharmacotherapy. 2012;32(10):e219.
20. Kumar B, Dahal P, Venkataraman R, Fuloria PC. Assessment of clinical pharmacist intervention in tertiary care teaching hospital of Southern India. Asian J Pharm Clin Res. 2013;6 Suppl 2:258-61.

21. Blix HS. Drug-related problems in hospitalised patients. A prospective bedside study of an issue needing particular attention [dissertation]. Oslo (Norway): University of Oslo, Faculty of Medicine; 2007 [cited 2015 Mar 1]. Available from: https://www.duo.uio.no/bitstream/handle/10852/ 28078/DUO_533_Blix.pdf?sequence=1 2 isAllowed $=y$

22. Pathways for medication safety: looking collectively at risk. American Hospital Association, Health Research and Educational Trust, Institute for Safe Medication Practices; 2002 [cited 2015 Mar 01]. Available from: www.ismp.org/tools/pathwaysection2.pdf

Elaine Lo, PharmD, is with the University of British Columbia, Vancouver, British Columbia.

Daniel Rainkie, PharmD, was, when this project began, a PharmD student at the University of British Columbia, Vancouver, British Columbia. He is now with the Qatar University College of Pharmacy, Doha, Qatar.

William M Semchuk, PharmD, FCSHP, is with Regina Qu'Appelle Health Region Pharmacy Services, Regina, Saskatchewan, and the University of Saskatchewan, Saskatoon, Saskatchewan.

Sean K Gorman, PharmD, is with Interior Health Pharmacy Services, Kelowna, British Columbia, and the University of British Columbia, Vancouver, British Columbia.

Kent Toombs, BScPharm, is with the Pharmacy Department, Nova Scotia Health Authority, Halifax, Nova Scotia.

Richard S Slavik, PharmD, FCSHP, is with Interior Health Pharmacy Services, Kelowna, British Columbia, and the University of British Columbia, Vancouver, British Columbia

David Forbes, BScPharm, MPA, is with Vancouver Island Health Authority Pharmacy Services, Nanaimo Regional General Hospital, Nanaimo, British Columbia.

Andrea Meade, BScPharm, is with the Pharmacy Department, Nova Scotia Health Authority, Halifax, Nova Scotia.

Olavo Fernandes, PharmD, FCSHP, is with the Pharmacy Department, University Health Network, and the University of Toronto, Toronto, Ontario.

Sean P Spina, PharmD, FCSHP, is with Vancouver Island Health Authority Pharmacy Services, Royal Jubilee Hospital, Victoria, British Columbia, and the University of British Columbia, Vancouver, British Columbia.

Competing interests: Kent Toombs was a co-investigator for an original research study on the topic of national clinical pharmacy key performance indicators for hospital pharmacists. No other competing interests were declared.

\section{Address correspondence to:}

Dr Sean P Spina

Vancouver Island Health Authority Pharmacy Services

Royal Jubilee Hospital

1952 Bay Street

Victoria BC V8R 1J8

e-mail: sean.spina@viha.ca

Funding: None received. 